\title{
Formas Y Deberes De LA JUSTICIA PoÉtica EN MUSUlmáN O BIOPOÉtica DE Julián AXAT
}

\author{
Emiliano Tavernini \\ Instituto de Investigaciones en Humanidades y Ciencias Sociales \\ Universidad Nacional de La Plata \\ Consejo Nacional de Investigaciones Científicas y Técinas \\ emiliotavernini@gmail.com
}

\begin{abstract}
Resumen: En este trabajo nos proponemos, en primer término, analizar el poemario musulmán o biopoética (2013) de Julián Axat con el objetivo de abordar un momento muy particular en la producción del autor en el que logra articular su trabajo como Defensor de Menores con la investigación académica y la escritura poética. En segundo lugar discutiremos con algunos abordajes críticos que se han realizado del poemario en un intento por establecer ciertas zonas de confluencia entre poesía, política $y$ memoria en la argentina reciente y sus efectos.
\end{abstract}

Palabras clave: Literatura argentina, Memoria, Hijos de desaparecidos.

\begin{abstract}
In this work we propose to analyze the poems first musulmán o biopoética (2013) by Julián Axat, with the aim of addressing a very particular moment in the author's production in which he manages to articulate his work as Defender of Minors with academic research and poetic writing. In the second place we will discuss some critical approaches that have been made of the poems in an attempt to establish certain areas of confluence between poetry, politics and memory in recent Argentina and its effects.
\end{abstract}

Keywords: Argentine literature, Memory, Children of disappeared. 


\section{Introducción}

El mismo año de la publicación de musulmán o biopoética (2013), decimocuarto título de la colección Los detectives salvajes de Libros de la Talita Dorada, Julián Axat publica su tesis para la obtención del grado de Magíster en Ciencias Sociales en la Facultad de Humanidades de la Universidad Nacional de La Plata titulada Una voz no menor: Apuntes etnográficos sobre la justicia penal juvenil. Ambos escritos se desarrollan de manera complementaria y abordan críticamente sus propias condiciones de producción. Escritura poética y académica intentan pensar políticamente la situación de los niños y jóvenes de las barriadas populares o que se hallan en situación de calle, y son continuamente negados y negativizados ${ }^{1}$ por los discursos hegemónicos y por su brazo performativo, el sistema jurídico que ejerce una violencia clasista y xenófoba sobre los destinos de los cuerpos que no se prestan dóciles a la normativización de las clases dominantes.

La sociología jurídica, pero especialmente la etnografía y los estudios culturales le van a proporcionar a Axat la distancia crítica necesaria para analizar su propia situación dentro del Fuero Penal Juvenil de la Provincia de Buenos Aires. El trabajo desempeñado por un defensor juvenil consiste, para explicarlo

\footnotetext{
1 Tomo este concepto de Mariana Cháves (2005): "las miradas hegemónicas sobre la juventud latinoamericana responden a los modelos jurídicos y represivos del poder. Tomando la propuesta foucoultiana sostengo que la juventud está signada por «el gran NO», es negada (modelo jurídico) o negativizada (modelo represivo), se le niega existencia como sujeto total (en transición, incompleto, ni niño ni adulto), o se negativizan sus prácticas (juventud problema, juventud gris, joven desviado, tribu juvenil, ser rebelde, delincuente, etc)" (p. 26).
} 
brevemente, en tener que asistir al lugar de detención de los menores, asesorarlos, ayudarlos en lo posible y prepararlos en todos los actos del proceso penal en el que estarán involucrados, particularmente cuando tenga que enfrentarse a otros actores del sistema judicial, Fiscales y Jueces:

Durante cada uno de estos turnos, cada una de las audiencias, cada entrevista, o encuentro con defendidos y demás actores fui tomando notas de lo que observaba. De los movimientos, de los guiños, de los comentarios, de los entretelones y anécdotas que conformaban cierta microcultura o mundillo simbólico que, una persona ajena al campo, difícilmente podría dar parte (Axat, 2013, p. 13).

Precisamente musulmán o biopoética va a tomar forma en ese mundillo, en los restos que el discurso académico va a seleccionar para dejar afuera en pos de cierta objetividad, como dirá en Rimbaud en la CGT (2014) "lo que el derecho no puede decir / Lo / dice un poema" (Axat, 2015, p. 20). Sin embargo, es interesante ver de qué manera el autor contrabandea literatura en los epígrafes de los capítulos, citando a André Bretón, John Berger, Moliére, Sharon Olds, incluso material incluido en su poemario como "Rap Máquina Hamlet"2, "Poroto" y la técnica para fabricar "bembas" y "Cavilación ante el puente generacional".

\footnotetext{
2 Reescritura del poema "teoría sobre el lenguaje docto ii (inercia deus ex machina)" de servarios (2005).
} 
Axat se vale de la poesía para penetrar y desestabilizar en sus bases ideológicas el sistema jurídico dentro del cual desarrolla su actividad laboral. Ya no blandirá sus armas discursivas desde una exterioridad, en la que la poesía actúa como un refugio del afuera, tal como leemos en los siguientes versos de ylumynarya (2008): "soldado/poeta/perro /¡la lírica a los perros! / sustituye a tiempo / ojos de funcionario / (objetivismo-mudoneutro-fósil) / por / diamantes en las calotas" (Axat ylumynarya 35); sino desde el material que puebla su práctica cotidiana de Defensor de Menores: artículos periodísticos, informes policiales, audiencias judiciales, diarios de campo de la tesis en curso, testimonios de las víctimas o de madres de las víctimas. Archivo abierto, revelado y visibilizado, en tanto material pretextual en la segunda parte del poemario, llamada PASAJES EN ESPEJO (Bitácora), singular ejercicio que interviene produciendo alteraciones en la sonoridad de la cita por medio de una versificación sui generis. El autor pone en funcionamiento una maquinaria de interpretación de la vida política que dejaron como legado Rodolfo Walsh y David Viñas, un ejercicio hermenéutico de extracción de la verdad en las entrelíneas del discurso del poder. Aunque podríamos pensar que en los últimos años se han dado profundas transformaciones culturales que hacen que la verdad sea dicha sin velos y que la interpretación del público actúe como el propio velo teledirigido, lo cual sería algo así como el efecto de "La carta robada" de Edgar Allan Poe llevado al plano de la política. 


\section{Una poética de resistencia}

El poemario se inicia con un epígrafe del poeta y profesor en derecho Friedrich Spee Von Langenfeld, jesuita alemán del siglo XVII, célebre por su libro Cautio criminalis en el que abogaba por la abolición de la quema de brujas y la tortura como método para arrancar confesiones a los acusados por la Inquisición. Axat promueve una reencarnación del jesuita desde su escritura, la nuda vida ya no serán las brujas sino los jóvenes de sectores marginales perseguidos y asesinados salvajemente por las fuerzas de seguridad, internados en Institutos de Menores o neuropsiquiátricos.

Uno de los problemas centrales del poemario se encuentra condensado en "El "Kitu" profetiza que la reja espera", poema que parodia "La verdad es la única realidad" de Paco Urondo: "Del otro lado de la realidad está la jaula / de este lado de la realidad también está la jaula / la única real es la jaula / irreal la realidad" (p. 26). Es interesante porque piensa una inversión de los términos, mientras que para Urondo lo irreal era la reja, y la realidad estaba tanto del lado de afuera como de adentro, en la vida del Kitu y todos los niños en su situación la jaula es la única verdad, y la realidad de las clases medias se convierte en lo irreal de un joven marginal. Esta idea se refuerza también desde el diseño gráfico, la solapa en lugar de llevar una foto del autor está ilustrada con el dibujo del identikit de un joven con una mira roja en la frente, marca de nacimiento o estigmatización cultural, el gatillo de un Estado disciplinador que cumple una función biopolítica de sospecha y disparo 
sobre la nuda vida. El poeta denuncia las vidas expulsadas por el biopoder $^{3}$ desde su nacimiento y cómo la celda se convierte en una especie de hogar, quizá el único al que tienen acceso estos chicos $^{4}$.

Desde un plano formal, como señala Mariano Dubin (2011), Axat "recupera el encabalgamiento trunco de Lamborghini, dejando palabras sueltas que violentan por lo no dicho" (p. 37) para hacer de esa imposibilidad "un recurso político-estético que permite escribir / registrar el canibalismo político de las clases dominantes" (p. 37). Así es que en esta elección se visibiliza una reapropiación o lectura a contrapelo de uno de los poetas reivindicados por la poesía de los ' 90 , pero que al igual que Joaquín Giannuzzi era leído dejando de lado o no prestando deliberada atención a la dimensión política de sus textos". Por otra parte, en algunos poemas como "Rap

\footnotetext{
${ }^{3}$ En general el biopoder según lo entiende Roberto Esposito, puede ser pensado como un mecanismo de distribución desigual entre "personas" y "cuerpos" (Giorgi, 2014, p. 200).

4 "La implementación en la Provincia de Buenos Aires de la ley 13.634 trajo aparejado un tipo de imaginarios y de prácticas inéditas hacia dentro de la agencia judicial, que hasta entonces estaban vinculadas a la ideología del Patronato de la Infancia impregnada a la actividad de los viejos actores de dicha agencia. Me refiero a la nueva construcción de un tipo de "peligrosismo", sin piedad, con menos concesiones, con una moralidad ya no "protectora", sino del "desprecio" o "banalidad del mal". El nuevo peligrosismo está basado en la defensa social y en la retribución al "menor delincuente peligroso", y no en la prevención especial positiva o en la situación irregular del "menor abandonado". Este cambio ideológico no puede ser pasado por alto a la hora de pensar la actividad actual de las agencias judiciales y la reproducción de un valor que define medidas tales como: penas perpetuas o excesivas, medidas de seguridad a inimputables, confinamientos con "engome" en tumbas de la prisión preventiva, convalidación sistemática de detenciones policiales arbitrarias, el internamiento en comunidades terapéuticas, y la psiquiatrización judicial por pobreza" (Axat, 2013, p. 210).

${ }^{5}$ Algo similar hará Nicolás Prividera en Tierra de los padres cuando recupere el poema "Progenitores" de Contemporáneo del mundo (1962) de Joaquín Gianuzzi para situar
} 
Máquina Hamlet" el yo lírico semeja su tempo con el de una máquina de escribir de la burocracia, las anáforas, las rimas y los repiqueteos repetitivos en un mismo lexema, junto con las aliteraciones, transportan al lector a un clima propio de las dependencias públicas. Muchas veces, la descripción realizada en los Cuadernos de campo revela una musicalidad insospechada, un trabalenguas jurídico que necesita ser dicho para develar la violencia en la que se justifica, precisamente en esta imposibilidad de ser comprendido radica su función social que oculta los mecanismos de regulación social a través de la exclusión, la xenofobia y la criminalización de la alteridad.

La estructura del poemario se encuentra sintetizada en el título. Retoma por un lado la figura del musulmán que describe Primo Levi y que analiza en profundidad Giorgio Agamben en tanto caso extremo de la vida desnuda en el contexto de los campos de concentración, para hacer referencia a los jóvenes que en la tesis de maestría va a denominar "cachivaches". Término extraído de la jerga carcelaria para hacer referencia a las personas que no se adaptan a las normas básicas de convivencia. Un sinónimo para el cachivache sería el "jugado", alguien que sale a delinquir porque es lo mínimo que se espera de él y la única forma que encuentra para poder seguir reproduciendo su vida. En contraposición encontramos la biopoética, que a diferencia de la biopolítica que actúa en tanto umbral que permite al poder soberano discernir qué vidas son las que merecen ser vividas y cuales son descartables para el

históricamente su figura y reivindicarlo de una manera tal vez más completa de la que fue leído en los ’90. 
Estado-Nación, la biopoética acapara, reúne, cobija, le da voz a esas vidas veloces cuya imagen final seguramente los encontrará tendidos en el asfalto producto de una balacera o en la puerta de un hospital con un paro cardiorrespiratoio producto del deterioro que produce la pasta base. A diferencia de la biopolítica que consume las vidas precarias, la poesía las va a eternizar en una sobrevida. Precisamente a esto hacían referencia Deleuze y Guattari (1978) cuando analizaban la potencialidad revolucionaria de una literatura menor: "si el escritor está al margen o separado de su frágil comunidad, esta misma situación lo coloca aún más en la posibilidad de expresar otra comunidad potencial, de forjar los medios de otra conciencia y de otra sensibilidad" (p. 30).

Este ejercicio que funda un espacio de justica en la poesía ya había sido abordado por Axat en médium. (Poética belli) (2006), allí retomaba la obra del espiritista francés Allan Kardec para postular un diálogo con los muertos mediante una sesión poética que posibilitaba el encuentro con sus padres desaparecidos. Estamos ante un procedimiento textual que permitiría ligar a las víctimas de la democracia con las víctimas de la última dictadura, dado que como recuerda Agamben, el poder soberano incluye en la estructura de su ordenamiento jurídico-político aquello que a la vez deja afuera y llama "'relación de excepción' a esta forma extrema de una relación que solo incluye algo a través de su exclusión" (Agamben,2005, p. 36).

El poema "Plaza San Jorge Mártir" trabaja sobre un caso tristemente célebre de la ciudad de La Plata, el de un grupo de niños que en su momento fue bautizado por la prensa amarilla 
como la Banda de las frazadas, porque según la fábula narrativa de los comerciantes de la zona utilizaban para robar a los peatones una frazada. Más allá de los delitos menores que pudieran haber cometido este grupo de niños, es interesante ver cómo actuó en este caso lo que Sara Ahmed (2015) denomina una economía afectiva del miedo, la cual expulsó del espacio público a niños y adolescentes etiquetados como peligrosos: "el miedo puede funcionar también como una economía afectiva: no reside de manera positiva en un objeto o signo particular. Esta falta de residencia permite que el miedo se deslice de un signo a otro o entre los cuerpos" (p. 107). La autora analiza de qué forma el miedo encoge el espacio corporal y social de los seres a los que se teme, dado que no involucra tanto la defensa de una frontera sino que contribuye a la construcción de fronteras de manera constante, de la misma manera que como explica Agamben (2005) "en la excepción soberana, en efecto, no se trata tanto de controlar o neutralizar un exceso, sino sobre todo de crear y definir el espacio mismo en que el orden jurídico-político puede tener valor" (p. 37). Los cuerpos que no estén habilitados por el poder soberano para circular por determinados espacios van a llevar una marca, como Caín. Para evitar confusiones: "la solidaridad está basada en la 'inseguridad' y no en la 'necesidad': las comunidades se convierten en una 'fuerza vinculante' mediante la percepción del riesgo compartido" ( $p$. 120), de esta manera se produce un deslizamiento sígnico originado en el temor que proyecta y adhiere signos a los cuerpos de niños o jóvenes pobres que deambula por la zona céntrica del casco urbano. Es interesante resaltar que "el miedo 
responde a lo que se acerca en vez de hacerlo a lo que ya está aquí" (Ahmed, 2015, p. 109), la movilidad espacial y social (que es un tópico de nuestra literatura del siglo XX y que surge con fuerza a partir del peronismo, por ejemplo en "La fiesta del monstruo" de Borges y Bioy Casares o "Casa tomada" de Cortázar) produce en quienes tienen la libertad de circular por el espacio céntrico porque o bien generan plusvalía o expresan potencialidad de consumo, una repugnancia similar a la que transmite una cucaracha, valga la ejemplificación kafkiana, cuando percibimos que corre a esconderse debajo de un mueble.

\section{El lugar de los hijos en la literatura argentina reciente. Una discusión}

En una ponencia denominada "Memoria de los padres, memoria de los hijos: musulmán o biopoética (2013) de Julián Axat" Mirian Pino plantea que poéticas como las de Axat o Emiliano Bustos son ajenas "a toda teorización que tienda a considerar el sujeto lírico como desrealización del autor, todo lo contrario, es la potencia de la memoria autoral la que inscribe los avatares del yo poético" (Pino, 2013, pp. 6-7), el argumento que blande es que advierte en los autores operaciones estéticas destinadas a clivar al yo y potenciar su historicidad "a inscribirlo como una representación artística de los autores", para ello se valdrían de distintas estrategias como la escritura de prólogos y dedicatorias, las notas a pie de página, archivos jurídicos, junto con "el ingreso de materia 
biográfica trabajada artísticamente". Más allá de que la intención autoral de los poetas intente construir un yo lírico "fundamentalmente histórico", como dice la autora, cosa que dudo, consideramos que el trabajo con el lenguaje poético implica tal como lo estudia Jorge Monteleone una irrealización por intermediación de un sujeto imaginario, el yo poético: "la condición misma del poema es que el yo se ausente, que sea su propio repliegue aquello que da lugar al poema. Ya que el lenguaje es, finalmente y por eso mismo, testamentario: el habla de un muerto" (p. 67).

Justamente la operación de musulmán o biopoética da cuenta de esa desubjetivación poética que superpone escritura, problemas y víctimas de diferentes períodos históricos en un yo lírico en permanente fuga (esta fuga en su siguiente poemario opera a partir del símbolo cultural nominal Rimbaud, que funciona como una especie de mantra), de hecho poemas como "Hip-hop alta Gama" son escritos, como aclara en nota al pie, a cuatro manos junto con J.D. un menor de 16 años, "Poroto' y la técnica de fabricar 'bembas"” es escrito junto con R.S. de 17 años, "Hip Hop de un canalla reclutador 7 Pound "\$” escrito con H.A.V. de 17 años, "Manifiesto escrito a seis manos", fue elaborado con R.G., J.G. y M.S. Ejercicios de desterritorialización de la lengua que traen a su escritura esa lengua no menor despreciada por el Estado. Procedimientos similares de disgregación lírica y subjetiva encontramos en abundancia en servarios, homenaje a Gilles Deleuze y a Lucrecio, poemario que sin lugar a dudas y desde el título "ser 
varios" trabaja sobre el devenir otro en la escritura ${ }^{6}$, o incluso antes en Peso formidable (2003) cuyo poema V dice:

"Umbral de placer / Cuerpo sin órganos (CsO) / escondite de las manos / SIN MONTAÑAS / planicie mutantes caricias nutren temblores / en mesas de diseccion que devienen / él / ELLO M.A.D.R.E.S. Y ANIMAL NADIE / hijo HIJOS yo / madres varios / TODOS ANDRÓGINO / P.U.T.O. padres MARGINAL hijo H.I.J.O.S. / otro / múltiple-identidad D.E.S.A.P.A.R.E.C.I.D.O.S. desaparecidos muertos (..)” (Axat, 2003, pp. 16-17)

Vemos aquí cómo Axat anticipa y juega con un procedimiento que será muy productivo también en Poemas bijos de Rosaura (2016) de Emiliano Bustos. Es decir, la deconstrucción de la figura del hijo, la explotación de la etiqueta en mil astillas que de alguna forma den cuenta de las vidas precarias sin caer en el lugar común, en lo ya dicho en el lenguaje codificado por la cultura y las instituciones. Bustos lo problematiza en su artículo "La poesía después" (2018): "la memoria de estas violencias está en permanente construcción, y la poesía puede avanzar y ser en ausencia de un relato central; un sinfín de ausencias y violencias no están todavía sujetas a la evidencia ética, casi moral de un discurso ya dicho, ya cristalizado por años y años de significación" (Bustos, s/n). De

\footnotetext{
${ }^{6}$ Escribió Esteban Rodríguez sobre el libro: “el servario también es el espacio abierto para desandar los surcos que la Institución grabó en nuestro cuerpo. El lugar para liberar la «anomalía salvaje», donde se cultiva la «alegre potencia a veces con alegría, a veces con miedo» (...) se trata de desindividualizarse. Despistar a «la máquina de convalidar letras y firmas», esa máquina inerte, en manos de «doctorcitos» bien lustrados en los que solemos convertirnos. Después de tanta disciplina, la consigna sería: «Multiplicación y desplazamiento», fugar" (Rodríguez, 2007, p. 28).
} 
hecho es interesante volviendo a las ideas de Deleuze y Guattari saber que cuando Axat pide colaboraciones para la antología La Plata Spoon River, homenaje y denuncia por las víctimas de la trágica inundación del 2 de abril de 2013, no envía a los poetas que quieren participar ningún dato biográfico de las víctimas de la inundación cuyo nombre servirá de título a los poemas. Acto de fe en la poesía y en su poder desterritorializante y reterritorializante de nuevos sentidos. Por otra parte, en el poema "Ser "Franco" \& la noche más oscura" de musulmán o biopoética hay una superposición productiva y democratizadora de la idea de víctima de los Gulag, de Guantánamo, de la última dictadura argentina y del gatillo fácil de la policía bonaerense. En "La poesía es / la boca" leemos:

"El poeta es Nadie / Nadie / testimonia / por el Testigo / o / Nadie / es poeta Testigo / Testimonia Nadie? / Nadie / testimonia / por el Testigo / El poeta no? / El poeta Nadie? / Paul Celan Nadie? / El Testigo es Nadie / pero / es Testigo / El poeta testimonia / luego / es Nadie” (p. 61).

Resumiendo, pensamos junto con los poetas que la poesía no es mero testimonio y que esto no imposibilita que el yo lírico que emerge en la escritura no contribuya a la construcción y la elaboración de la memoria histórica de / con los lectores. Intuimos en estos abordajes críticos, dado que el de Pino no es el único y sólo sirve de muestra ${ }^{8}$, los peligros de

\footnotetext{
7 Algo similar señalaba Matías Moscardi en una reseña crítica a propósito de la publicación de la antología crítica La tendencia materialista de Damian Selci, Violeta
} 
una construcción literal de la memoria, seguramente que desde un posicionamiento político progresista no digo que no; y no de una memoria ejemplar tal como planteara Tszvetan Todorov, es decir de una articulación de experiencias a través del lenguaje que sirva de modelo para comprender situaciones nuevas.

También Fernando Reati aborda este poemario en el trabajo "De los desaparecidos de los '70 a los menores marginados de hoy: Julián Axat y la defensa de la poesía como nuda vida" (2017), allí plantea en un momento que Axat realiza el camino inverso que emprende Julián López en la novela Una muchacha muy bella (2012). Es decir, lo que Marianne Hirsch denomina posmemoria afiliativa. López inventa un narrador que funciona como agente transmisor de memoria creando un espacio de

Kesselman y Ana Mazzoni: “me interesa subrayar, precisamente, cierta concepción residual, diría Raymond Williams- de la literatura como reflejo del mundo social. En los poemas de Casas, Rubio, Cucurto, Gambarotta y Raimondi, incluso en los poemas de Fernanda Laguna, aparece, efectivamente y sin duda, cierta representación de una realidad social determinada. Ahora bien, lo que quiero decir es que Kesselman, Mazzoni y Selci, por momentos, leen/analizan esas representaciones en términos casi "realistas"” (Moscardi s/n). La antología está dividida en apartado denominados "La percepción cultural" que reúne poemas de Desiderio, Casas y Laguna, "La percepción política" con poemas de Gambarotta, Cucurto y Rubio y "La percepción histórico-social" dedicada a Sergio Raimondi, en este sentido el análisis de Pino contribuiría con un nuevo capítulo "La percepción de la memoria histórica". Como dije, tomo el texto de Pino porque analiza específicamente un poemario de mi corpus de investigación, pero la misma lectura se encuentra en abundancia, por lo general, cuando disciplinas como la historia o la sociología abordan ficciones.

${ }^{8}$ En un artículo sobre Offshore la autora incluso se acerca bastante a la idea de literatura que guía nuestro trabajo: "la poesía es el lugar de reparación y una nueva forma de entender la subjetividad no como una territorialidad del yo sino como el lugar de una colectividad deportada y paradójicamente necesaria para el Estado" (Pino, 2017, p. 164). El subrayado es nuestro) y valoramos la clave de lectura que propone, incluso para un corpus más abarcativo, cuando hace foco "en la emoción como construcción política, con nuevo lugar de agenciamiento" (p. 168). 
recuerdo más allá de lo familiar, de lo filiativo, este acto establece una relación intersubjetiva particular o aloidentificativa con las víctimas, "su práctica de la posmemoria puede erigirse en un acto ético y político reparativo de solidaridad" (Hirsch, 2015, p. 140). Sin embargo hay peligros en esta apropiación por mas bienintencionada que sea, hablamos de la identificación que produce una estética de la empatía ${ }^{9}$, es decir, lo que Carlos Gamerro denomina el deseo de ser hijo de desaparecidos en los lectores de esta literatura ${ }^{10}$.

${ }^{9}$ Félix Bruzzone en Los topos (2008) construye el personaje de Romina, la novia del protagonista que no es hija de víctimas del genocidio pero que sin embargo dedica su vida a militar en H.I.J.O.S., paradójicamente este personaje adoptará los posicionamientos más radicales e intolerantes.

${ }_{10}$ Dice Gamerro en Facundo o Martín Fierro. Los libros que inventaron la Argentina (2015) que en los '90 con la emergencia de H.I.J.O.S. un profesor de psicología en la escuela donde daba clases le comentó que una de las fantasías más comunes de los alumnos era la de ser hijos de desaparecidos "podría pensarse que no hay nada peor que ser hijo de desaparecidos, pero ninguna fantasía está regida por el miedo o la paranoia únicamente: todas están investidas en menor o mayor medida por el deseo. Para el niño que siente que no hay nada peor que ser hijo de estos padres, la idea puede resultar muy atrayente: 'Mis verdaderos padres eran héroes y ustedes son unos inmundos apropiadores cómplices de la dictadura"' (Gamerro, 2015, p. 522) De manera análoga para López, según Gamerro, por haber perdido a su madre a la edad de 10 años en un accidente civil esta fantasía puede funcionar como un alivio o consuelo. Ironiza el autor diciendo que Una muchacha muy bella puede llevar de subtítulo Sobre el deseo de ser hijo de desaparecidos. Recordemos que Gamerro escribió esa exquisita novela coral que es El silencio y las voces (2001) con un personaje principal que es hijo de desaparecido, y que sin embargo no problematizaba de manera directa su rol en la sociedad a partir de una estetización afectiva de sus recuerdos sino mas bien apuntaba a develar los silencios, las negaciones y las complicidades civiles de un pueblo en el que aparentemente no pasaba nada. Vemos en el novelista un movimiento semejante a las críticas que planteara Nicolás Prividera a propósito de Los rubios de Albertina Carri, es decir, correr el riesgo de al no analizar histórica, política y críticamente la vida de los padres, caer en una visibilización solipsista del dolor por su ausencia. Otra novela que retoma la voz de los hijos es Lengua madre (2010) de María Teresa Andruetto pero no bajo una configuración narrativa pática sino que a partir de lo que Mandolessi (2016) definiría como tradición realista, propone y apuesta por una lectura política y crítica de los ' 70 , la hija de la novela debe arreglar cuentas no con sus padres solamente sino con la época en la que ellos vivieron, lo cual permite dar cuenta de lo necesario de una elaboración colectiva que deje de negar o renegar de los hechos, para poder elaborar la historia familiar. 
Nicolás Prividera no le escapa a la polémica cuando lo entrevistamos:

hay una apelación estética que tiene que ver con una vampirización de la experiencia y cierta estetización de la memoria, con todas sus variantes para bien o mal. Digo: no todas [las novelas de la denominada narrativa de hijos] buscan esa especie de objetivación poética del pasado, como la novela de Julián López (...) Hay algo en toda esa narrativa, y en cierto cine también, que no logra salir de esa condición de hijo, por decirlo así, y encima la convierte en una especie de identificación tramposa. Todos tenemos padres y todos mueren tarde o temprano. Lo que sin duda hace que pueda funcionar en términos de mercado, pero como arte no solo es poco interesante o estimulante, sino un poco abyecto en algunos casos. En el mejor de los casos, es como una mirada fantasmal sobre el pasado, que pese a su aparente distancia crítica no logra articular ni algo nuevo y ni una posición propia (Entrevista a Prividera 03/01/2018).

Nos preguntamos si estamos ante un recorrido inverso tal como plantea Reati o ante dos producciones guiadas por concepciones político-ideológicas diferentes. Cito a Reati:

López explica que lo hace porque no haber sufrido la represión en carne propia no le impide sentirse parte de una comunidad sufriente, y dice en una entrevista: "Hay que salir de la idea de víctima y complejizar los temas. La idea de la víctima excede ese momento particular [de los 70]..." (Mannarino, 2014). Axat pareciera recorrer el camino inverso para encontrarse con López en el mismo 
punto, en el sentido de que a partir de su propia victimización como hijo de desaparecidos llega a trascender su experiencia personal y, a través de la empatía, abraza a las víctimas de otras situaciones. Axat explica en una entrevista que le interesan "las voces de los que no tienen voz, ya sea porque no pueden hablar, porque ya están muertos, porque son literalmente menores, parias, marginales, desaparecidos de la historia (Reati, 2017, p. 20).

Aquí surge una de las paradojas que diferencia la obra de Axat de la propuesta de López, éste publica su novela en el momento en que los hijos son reconocidos por el Estado, a ellos apuntan varias leyes reparativas en el contexto de reapertura de los juicios por Crímenes de Lesa Humanidad, de hecho se convierten en figuras públicas porque dan continuamente testimonio en los medios de comunicación o en los estrado, incluso por su militancia muchos son funcionarios o legisladores, sin hablar de las múltiples manifestaciones artísticas que los cuentan como autores en las que revisitan críticamente a la generación del '70. Además, este ponerse en el lugar de la víctima que intenta el ejercicio poético de López debería leerse con ambivalencia, consideramos que el momento más interesante de la novela se encuentra sobre el final cuando el narrador está hablando sobre la necesidad de salir de su cuarto, de su encierro, que podríamos interpretar como la condición de víctima en la que se encuentra:

salir a la calle para respirar una enorme bocanada, para acercarme a esas chicas que no cuentan más de 14 años y tienen los breteles caídos de los hombros transpirados. 
Esas nenas que se ríen mientras tiran de la cincha de un enorme carro cartonero en la avenida entre los autos. Esas morenitas alegres que se disputan un heladito que se les derrite por la risa, por la fuerza de tirar de esa mahoma de celulosa que va por la avenida junto al murallón y es cuna de un bebé que duerme su borrachera de mamadera vacía en la boca como chupete. Y yo que corro con la boca abierta para tragarme todo el aire de esas carcajadas y no sé qué hago y mucho menos sé qué hacer y les grito ¡chicas! Y las alcanzo y paro casi sin poder respirar y me agacho antes de mirarlas, antes de preguntarles de qué se ríen. Y ellas, sorprendidas, se dan vuelta y dejan de reírse y me miran agitado y en cuclillas y tal vez enojadas porque van a tener que arrancar esa mole pesadísima que mi grito les hizo detener y se miran entre sí porque no saben cómo reaccionar y vuelven a mirarme. $Y$ se ríen otra vez con esas carcajadas llenas de aire. Y me miran y se ríen. Se me cagan de risa. Y yo respiro (López, 2012, 157).

Por un lado tenemos un escritor que construye un protagonista con la madre desaparecida, que se pone en el lugar de la víctima pero que al mismo tiempo cuestiona o polemiza con la idea de que sea la única víctima, de ahí la aparición de las cartoneritas y esa risa que perturba sobre el final, pero que ambiguamente le permite respirar al personaje: ¿se saca un peso de encima?¿se atempera el dolor propio siendo consciente de que hay otros dolores? ¿por qué una risa y no una mirada de dolor, de compasión por un sujeto en calzoncillos en una calle?. Miriam Chiani (2016) propone una 
hipótesis de lectura muy acertada de este cierre, cuando lo considera una culminación de un ejercicio de rememoración:

un ejercicio próximo al proceso de duelo -el esforzado y lento desligarse de la repetición; la paulatina renuncia de ese sintagma, "Mi madre era una muchacha muy bella", especie de mantra que convoca, escande y sostiene los recuerdos-; proceso que culmina con el abandono final de ese lugar de memoria -el cuarto, el escritorio, santuario o templo, espacio de veneración de la imagen materna- para salir y respirar en la calle (Chiani, 2016, 10).

En todo caso el cuestionamiento de Prividera pone el foco en cierta modalidad enunciativa que se emparenta con lo que Mandolessi (2016) denomina configuración pática del abordaje a los '70, en el sentido de que más que brindar explicaciones o proponer una reflexión crítica sobre la historia argentina predomina la emoción que suscita la violencia y supone automáticamente la empatía del lector por esa tremenda aflicción narrada.

Si bien el final queda abierto y no es objeto de la literatura resolver todas las cuestiones intuyo que en ese cierre de López ronda la idea que plantea y trabaja Washington Cucurto de una manera seguramente más conservadora y banal con su "Poema de la 125"de Hombre de Cristina (2013):

También soy un hijo de desaparecido. / A mí también me torturaron / y de hecho me torturan. / Hace 24 hs., que 
me chupan sin parar. / Cada día que comienza hacen 24 hs... / Cada día que comienza ya pasaron para mí / sus 24 horas de una tortura o chupamiento. / No es más fácil que antes. / La situación es esta. Soy un desaparecido presente. / Mi jerarquía política no es más grande que mis dudas humanas (...) / (Yo) que estoy tirado en la cama / muerto, quemado, degradado / por las circunstancias, sin laburo, / con cuatro hijos Para alimentar, / no sirvo ni para extra de desaparecido. /Soy el tipo que pasa por la esquina. / gordo, feo, mal vestido, sin un peso. / Soy el tipo para el cual las cosas son más complicadas / de lo que deberían. / No es más fácil que antes. Mientras muchos reciben dinero / por la sangre derramada (sangre que no les corresponde) / y eso da cierto estatus social, cierto acomodo económico, / sin el menor esfuerzo, / sin el mayor sacrificio / explotando el árbol genealógico / el derecho del vínculo / de un ser que no existe más que en el recuerdo. / No es lo mismo (...) (Cucurto, 2013, p. 12).

Aquí encontramos una lectura muy común realizada por una zona amplia de la oposición al kirchnerismo que veía a los hijos de militantes asesinados por la práctica social genocida como parásitos enquistados en el Estado kirchnerista. Una imagen negativa de las leyes reparatorias ${ }^{11}$ similar a la que planteara el entonces candidato a presidente Mauricio Macri

11 Un trabajo aparte sería analizar de qué forma los hijos utilizan el dinero que les da el Estado como forma de reconocimiento por sus crímenes. Como ejemplo y sin dar el nombre, uno de los poetas que estudio decidió destinar ese dinero a ayudar a la gente de la villa en la que su madre realizaba trabajo barrial. Indagó entre los vecinos para saber quienes tenían deseos de realizar estudios universitarios y a los seleccionados les creó una cuenta en la que todos los meses transfiere dinero para que puedan dedicarse a su formación sin otra preocupación. 
cuando alertaba a los medios de comunicación que había que terminar con "el curro de los derechos humanos"12. La confluencia discursiva de Washington Cucurto como exponente de la literatura de los ' 90 con el líder de la coalición de ultraderecha que hoy gobierna la argentina no es casual. Para comprender la cuestión de fondo o lo que se pone en juego en ese poema tal vez habría que recordar que Vega quiso renunciar en su momento a la marca nominal inventada por Daniel Durand y mitificada por Fabián Casas y no pudo. Santiago Vega no vende, Cucurto $\mathrm{si}^{13}$. Se nos hace banal incluso en el análisis recordar que todavía hay casi cuatrocientas personas apropiadas desde niños que no conocen a su verdadera familia biológica y que todavía son buscados. Es extraña la paradoja de un yo lírico que simula un personaje marginal, definido por la explotación laboral que ¿defiende la 125?, no lo sabemos, al menos lo sugiere el título del poema, a lo mejor mera resonancia de algo no definitorio para su destino y que se escucha como al pasar. No cuestionamos la imagen de autor que, como tantas veces recuerda Vega en entrevistas, es un personaje imaginario que no tiene nada que

12 La frase fue publicada el 04 de diciembre de 2014 en el diario La Nación con el título "Mauricio Macri: "Conmigo se acaban los curros en derechos humanos"”. En su último poemario Offshore (2016) Julián Axat aborda este tópico recurrente en la oposición por derecha al kirchnerismo en el poema "La moda de la víctima": "Está de moda ser víctima / -dijo el poeta- / para luego hacerse la víctima / de un grupo de poetas / que lo blasfemaban / y decían que sus sonetos / apestaban a la herida de quien / no tiene un motivo más que la / impostura de una memoria marcial. / "Está de moda hacerse la víctima" / dijo otro de la tertulia / que lo corrigió / y terminaron chocando las copas / entre poetas que no lo blasfemaban / y yo solo miraba de lejos / con la farsa del victimario" (Axat, 2017, p. 10).

13 "Los escritores no están acostumbrados al marketing, pero a mí me gusta porque desconfío de las cosas serias, y si los escritores siguen manteniendo ese perfil tan serio, no llegan a la gente. Tampoco estoy diciendo que el marketing sea la mejor manera de llegar; es sólo una" (Friera s/n). 
ver con sus opiniones personales, sino que nos preguntamos qué implicancias político-ideológicas representa el yo lírico que construye. Retomando a Axat, es un cachivache bardero pero que en su representación de lo popular marginal, negativiza tanto al negro como al musulmán, que funcionan como títeres que dicen el discurso del poder y defienden valores neoliberales. Esta perspicacia acomodaticia que señalamos es la que se propuso guillotinar Axat en la presentación de la antología si Hamlet duda le daremos muerte en el año $2010^{14}$, la idea la tomó del texto "Tengo miedo" de Evgeni Zamiatin, recopilado en las Cartas a Stalin (2010):

Con desdeñoso decreto, la revolución francesa guillotinaba a los poetas cortesanos disfrazados de revolucionarios. Y nosotros «a esos autores perspicaces que saben cuando ponerse el gorro rojo y cuando quitárselo», cuándo cantar loas al zar, y cuando a la hoz y al martillo, los presentamos al pueblo como representantes de una literatura digna de la revolución. Y ellos, centauros literarios, golpeándose unos a otros y dándose coces, corren en competición por un magnífico premio. El derecho exclusivo a escribir odas, el derecho exclusivo a cubrir de barro a la intelligentsia (...) tengo miedo que si las cosas siguen así en el futuro, el último período de la literatura rusa entre en la historia con el nombre de la escuela perspicaz, pues los que no son

14 En Tavernini (2017) abordamos en profundidad la polémica que generó esta performance. Para ubicar al lector valga mencionar que en la presentación de la antología se guillotinó un ejemplar de Horla City de Fabián Casas como metáfora de la necesidad de romper con la poesía, los poetas, la crítica y los medios de legitimación de los '90. 
perspicaces ya hace dos años que callan" (Zamiatin, 2010, pp. 67-68).

\section{Palabras finales}

Para finalizar, consideramos que en musulmán o biopoética Axat con su propia obra, poética y jurídica ya responde o se anticipa a la polémica que intenta abrir López. musulmán o biopoética y Una voz no menor dan cuenta de estos intentos de salirse del lugar de víctima, para reconocer y reconocerse el sufrimiento de los otros, en un intento por analizar las continuidades de la democracia en dictadura, ya sea en lo que refiere a la familia judicial como a la violencia institucional, ejemplo de esto son los poemas "Iván no tiene entidad / no está / es una incógnita" o "Restos de restos de restos de restos de restos...". En el primero se parodia una declaración conocida de Videla en la que instaura la idea de desaparecido para dar cuenta de un caso actual, mientras que en la segunda remitiendo a restos de restos (2011) de Nicolás Prividera se superpone la figura de distintos asesinatos: un joven Qom de Formosa, con una mujer guerrillera y otros jóvenes menores víctimas de la violencia institucional en Tolosa, Rosario, Punta Lara. 


\section{Referencias Bibliográficas}

Agamben, G. (2005). Estado de excepción. Buenos Aires: Adriana Hidalgo.

Ahmed, S. (2015). La política cultural de las emociones. México: Fondo de Cultura Económica.

Axat, J. (2003). Peso formidable. Buenos Aires: Zama. (2005). Servarios. Buenos Aires: Zama, 2005. Dorada. (2008). ylumynarya, City Bell, Libros de la Talita (2013). Una voz no menor: Apuntes etnográficos sobre la justicia penal juvenil. Tesis de posgrado, Facultad de Humanidades y Ciencias de la Educación, UNLP. (2013). musulmán o biopoética. City Bell: Libros de la Talita Dorada.

(2015). Rimbaud en la C.G.T.. City Bell: Libros de la Talita Dorada.

(2017). Offshore y otros poemas. Buenos Aires: Ediciones periféricas, 2017.

Bustos, E (2018). "Poesía y después". Recuperado de https://elniniorizoma.wordpress.com/2018/o2/13/la-poesiadespues/.

Cháves, M. (2005) "Juventud negada y negativizada: Representaciones y formaciones discursivas vigentes en la Argentina contemporánea”. Última década, 23, 9-32.

Chiani, M (2016). "Diarios de duelo". Identidades revulsivas. Lecturas críticas sobre la escritura de los HIJOS. Villa María, Eduvim. En prensa.

Cucurto, W. (2013). Hombre de Cristina. Bahía Blanca: Vox Senda. 
Deleuze, G. y Guattari, F. (1978). Kafka. Por una literatura menor. México: Ediciones Era.

Dubin, M. (2014). " Si no hay justicia hay poesía'. musulman o biopoética de Julián Axat”. Las patas en la fuente, 1.

Friera, S. (o5 de enero de 2007). "El personaje hace cosas que Santiago Vega nunca haría”, Página 12.

Gamerro, C. (2015). Facundo o Martín Fierro. Los libros que inventaron la Argentina. Buenos Aires: Sudamericana.

Giorgi, G. (2014). Formas comunes. Animalidad, cultura y biopolítica. Buenos Aires: Eterna Cadencia.

Hirsch, M. (2015). La generación de la posmemoria. Escritura y cultura visual después del Holocausto. Madrid: Carpenoctem.

López, J. (2012). Una muchacha muy bella. Buenos Aires: Eterna Cadencia.

Mandolessi, S. (2016). "Narrativas espectrales en la literature postdictatorial Argentina". L. Feierstein y L. Zylberman (eds.). Narrativas del terror y la desaparición en América Latina, Buenos Aires: Eduntref.

Monteleone, J. (2016). El fantasma de un nombre. Poesía, imaginario, vida. Rosario: Nube negra.

Moscardi, M. (2013). "Todo lo sólido se desvanece en el aire". Bazar americano, Mar del Plata.

Pino, M. (2013). "Memoria de los padres, memoria de los hijos: musulmán o biopoética (2013) de Julián Axat”, Colloque International "Memoria en la ficción, ficción en la memoria: entre el ritual y la crítica”, Lyon, Universite Lyon, 2.

(2017). "Offshore, de Julián Axat: los susurros de la memoria”. Tintas. quaderni di letterature iberiche $e$ iberoamericane, 7, 161-169. 
Reati, F. (2017). "De los desaparecidos en los 70 a los menores marginados hoy: Julián Axat y la poesía como defensa de la nuda vida”, II Congreso Internacional de Literatura $y$ Derechos Humanos, México, Universidad Nacional Autónoma de México.

Rodríguez, E. (2007). "Servarios para King Kong”, el espiniyo, 6/7, City Bell.

Straccali, E (2017). "Julián Axat: la máquina imposible”. B. Crisorio y E. Straccali (coord.). Atlas de la poesía argentina, La Plata: EDULP.

Tavernini, E. (2017). "Poesía, política y memoria en la Argentina kirchnerista. La colección de poesía Los Detectives Salvajes (2007-2015)", Izquierdas, 37, Santiago de Chile.

Zamiatin, E. (2010). “Tengo miedo”. M. Bulgakov y E. Zamiatin, Evgeni, Cartas a Stalin. Madrid: Veintisiete Letras.

\section{Fuentes}

Entrevista realizada a Julián Axat el 26-02-2018 en el Restaurant El Portal y en su oficina de la Procuraduría General de la Nación.

Entrevista realizada a Nicolás Prividera el 03/01/2018 en el bar del Centro Cultural de la Cooperación Floreal Gorini. 